\title{
Molecular assembly of mitogen-activated protein kinase module in ras-transformed NIH3T3 cell line
}

\author{
Ki-Sook Park ${ }^{1}$, Jin-Ah Kim ${ }^{1}$ and \\ Kyong-Ja Chai ${ }^{1,2}$ \\ ${ }^{1}$ Department of Biochemistry and Molecular Biology, Institute of \\ Genetic Science, Yonsei University College of Medicine, Seoul \\ 120-752, Korea \\ ${ }^{2}$ Corresponding author: Tel, +82-2-361-5186; Fax, +82-2-312-5041; \\ E-mail, yha111@yumc.yonsei.ac.kr
}

Accepted 8 September 2000

Abbreviations: ERK, extra-cellular signal regulated kinase; MAPK, mitogen-activated protein kinase; EGF, epidermal growth factor; LTR, long terminal repeat

\begin{abstract}
The ras, is a G-like protein that controls the mitogenactivated protein kinase (MAPK) pathway involved in control and differentiation of cell growth. MAPK is a key component of its signaling pathway and the aberrant activation may play an important role in the transformation process. To better understand roles of ras in the activation of MAPKs, we have established ras transformed NIH3T3 fibroblast cell line, and analyzed the MAPK module. The ras transformed cells formed numerous spikes at the edges of cells and showed loss of contact inhibition. The levels of ERK1/2 MAPKs as revealed by Western blot analysis were not significantly different between ras transformed and non-transformed cells. However, phosporylation of ERK MAPKs and the level of MEK were significantly increased although the heavily expressed level of Raf-1, an upstream component of MAPK pathway was unchanged in ras transformed NIH3T3 cells. The sedimentation profile of the MAPK module kinases in a glycerol gradient showed the presence of a rather homogenous species of multimeric forms of ERK $1 / 2$ and MEK as indicated by the narrow distribution peak areas. The broad sedimentation profile of the Raf-1 in a glycerol gradient may suggest possible heterologous protein complexes but the identification of interacting molecules still remains to be identified in order to understand the organization of the MAPK signal transduction pathway.
\end{abstract}

Keywords: ras-transformed cell line, MAPK module, ERK, MEK, Raf-1

\section{Introduction}

Mitogen-activated protein kinases (MAPKs) are serine/ threonine kinases and well conserved in all eukaryotes (Pelech et al., 1992; Davis, 1993). The MAPKs are activated by series of phosphorylation cascade by upstream MAPK module kinases, MEK and Raf-1 (Blenis, 1993; Egan et al., 1993). The components of MAPKs module are rapidly and transiently activated by growth stimulatory signals in many types of cells, suggesting that they play important roles in cellular growth control. The activity of MAPKs is positively regulated by phosphorylation on both threonine and tyrosine residues (Anderson et al., 1990; Payne et al., 1991). Many transforming oncogenes encode mutant proteins whose cognate wild-type proto-oncogene products are components of signal transduction networks (Bos, 1989; Slamon et al., 1989; Bargmann et al., 1993). Transformation of cells induced by oncogenes is mostly mediated by modification of the protein (mainly phosphorylation) as well as an increase in the level of the protein (Slamon et al., 1989; Anderson et al., 1990; Tsutsumi et al., 1990; Blenis, 1993; Burgering et al., 1993; Janes et al., 1994). Of the oncogenes activating MAPK system, ras is one of the best known oncogene so far studied, and constitutive active mutants were found in many human cancers (Bos, 1989; Gallego et al., 1993). The ras family comprises a group of closely related transforming genes that are highly conserved in eukaryotes (Hall, 1992). The ras group includes $\mathrm{H}$-ras, $\mathrm{K}$-ras, and $\mathrm{N}$-ras and the level of gene expression varies in different tissues and cell types. Cellular studies of Ras suggested that the transformation occurs through two stage processes as follows: 1) activation of ras mutant found in human tumors, i.e. transformation of primary fibroblasts supplemented with immortalizing oncogenes such as myc (Land et al., 1983), an adenovirus E1A (Ruley, 1983), mutant p53 or polyoma large $\mathrm{T}$ antigen gene (Linzer et al., 1979), 2) overexpressing normal Ras protein [transformation of NIH3T3 cells (Chang et al., 1982; Ricketts et al., 1988)], caused either by multiple copies of ras genes or by linking low numbers of the genes to retroviral long terminal repeat (LTR) elements. Thus the Ras-transformed NIH3T3 cells became one of the best models to study the biology of cancers cells.

So far, most studies have been focused on the modification (i.e. phosphorylation/dephosphorylation) or quantitative aspects of MAPK module in various types of cancer cells. However, the signal transduction dependent molecular assembly of the MAPK module components 
was not characterized well. In this study, we have established ras transformed NIH3T3 cell line as a tumor model and have examined the level of expression and modification of MAPK modules. Furthermore, molecular assembly and disassembly of the MAPK module proteins in the NIH3T3 cells were investigated under conditions with or without induction by epidermal growth factor (EGF).

\section{Materials and Methods}

\section{Antibodies}

Anti-MAPK rabbit polyclonal antibody was purchased from Stratagene [La Jolla, CA, USA). Phospho-specific MAPK antibody (raised against synthetic phospho-tyrosine peptide corresponding to residues 196 to 209 (DHTGFLTEY (P)VATRWC) of human ERK2] was purchased from New England Biolabs, Inc. (Beverly, MA, USA). Anti-MEK and anti-c-Raf-1 antibodies were purchased from Transduction Laboratories (Lexington, KY, USA). Horseradish peroxidase conjugated secondary antibodies were also purchased from Transduction Laboratories.

\section{Cell culture and ras transfection}

NIH3T3 cells were purchased from the American Type Culture Collection (Rockville, MD, USA). The NIH3T3 cells were transformed with a Hindll-EcoR1 fragment of pNRSac (Murray et al., 1983) containing N-ras-oncogene. The cells were grown in Dulbecco's Modified Eagle's medium (DMEM) supplemented with $10 \%$ fetal calf serum (FCS), 100 units of penicillin, and $100 \mathrm{mg} / \mathrm{ml}$ of streptomycin as well as $0.7 \mathrm{mg} / \mathrm{ml}$ of G418 (Gibco/BRL. Gaithersburg, MD, USA). The cells were grown at $37^{\circ} \mathrm{C}$ in $5 \% \mathrm{CO}_{2}$ air mixture. Transformed cells were removed from foci by trypsin treatment and the stable cell line was established by selection with G418. The medium was replaced every three days for 3 months. For growth factor effect, cells were exposed to epidermal growth factor (EGF, $100 \mathrm{ng} / \mathrm{ml}$ ) and incubated at $37^{\circ} \mathrm{C}$ for 15 $\min$.

\section{Extract preparation}

Cells were rinsed twice with ice cold phosphate buffered saline (PBS) and harvested by scraping in ice-cold PBS. After addition of $0.5 \mathrm{ml}$ of PBS, the cells were centrifuged down and resuspended in $300 \mu$ of lysis buffer (70 $\mathrm{mM} \beta$-glycerophosphate $\mathrm{pH} 7.2,0.1 \mathrm{mM}$ each meta-

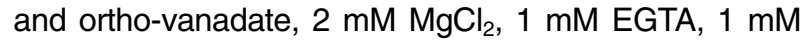
dithiothreitol (DTT), 0.5\% Triton-X-100, $0.2 \mathrm{mM}$ phenylmethylsulfonyl fluoride (PMSF), and $5 \mu \mathrm{g} / \mathrm{ml}$ each of pepstatin $A$, chymostatin, leupeptin, peptin, respectively). After incubation of the sample on ice for $30 \mathrm{~min}$, the samples were sonicated for $20 \mathrm{~s}$ and unbroken cellular debris were removed by centrifugation at $23,000 \mathrm{~g}$ for
$10 \mathrm{~min}$. The supernatant was further cleared by a subsequent centrifugation. Samples were immediately aliquoted and frozen at $-80^{\circ} \mathrm{C}$. Protein concentrations were determined with Bio-Rad protein assay kit (BioRad Laboratories, Richmond, CA, USA).

\section{Western blot analysis}

The lysates containing 40-100 $\mu \mathrm{g}$ of protein were subjected to $10 \%$ SDS-PAGE (Moon et al., 1999) and proteins were transferred onto a nitrocellulose membrane (Protran, Schleicher and Schuell Corporation, Dassel, Germany). Blots were incubated in the blocking solution (20 mM Tris-Cl, pH 7.5, 150 mM NaCl, 0.05\% Tween 20 (TBST) containing 5\% nonfat Carnation milk). Immunoblots were then washed with TBST and incubated for 2 $\mathrm{h}$ at room temperature or overnight at $4^{\circ} \mathrm{C}$ with the blocking solution containing appropriate amounts of primary antibodies. The blots were then washed and incubated with the blocking solution containing appropriate secondary antibody for 1 to $2 \mathrm{~h}$. After washing, the blots were developed with Amersham ECL kit (Amersham International, Buckinghamshire, UK).

\section{Glycerol gradient ultracentrifugation}

For glycerol gradient experiments, protein was concentrated to $10 \mathrm{mg} / \mathrm{ml}$ by using Amicon centricon (Amicon, Inc., Bererly, MA, USA). One hundred and fifty $\mu$ l of cell extracts $(10 \mathrm{mg} / \mathrm{ml})$ were used for glycerol gradient centrifugation. $10 \%$ and $30 \%$ glycerol $(\mathrm{w} / \mathrm{v})$ were prepared in modified $\mathrm{H}$ buffer (Elion et al., 1993) containing 150 $\mathrm{mM} \mathrm{NaCl}$. A linear 10 to $30 \%$ glycerol gradient in a total volume of $11.4 \mathrm{ml}$ was generated at $4^{\circ} \mathrm{C}$ cold room in a SW41 pollyallomer tube with a Hoefer SG13 gradient maker and peristaltic pump. One hundred and fifty $\mu \mathrm{l}$ of whole cell extract in modified $\mathrm{H}$ buffer containing 150 $\mathrm{mM} \mathrm{NaCl}$ was loaded onto a top of glyerol gradient. Molecular weight standard was loaded onto an identical $10-30 \%$ glycerol gradient. Gradients were centrifuged at $220,000 \mathrm{~g}$ at $4^{\circ} \mathrm{C}$ for $22 \mathrm{~h}$ in an SW41 rotor. Samples were removed with a $10 \mu \mathrm{l}$ capillary pipet attached to narrow tubing to withdraw $570 \mu \mathrm{l}$ aliquots from the bottom of each tube. One hundred and fifty $\mu$ of each aliquots of the fractions was used for immunoblot analysis.

\section{Results}

\section{Morphologies of NIH3T3 cells and ras-transformed cells}

A stable NIH3T3 cell line transformed with ras oncogene was obtained by transformation of ras gene followed by neomycin selection. The ras-transformed cells were characterized by the loss of contact inhibition and spikes budding out of the cells (Figure 1B). In order to confirm 
A.

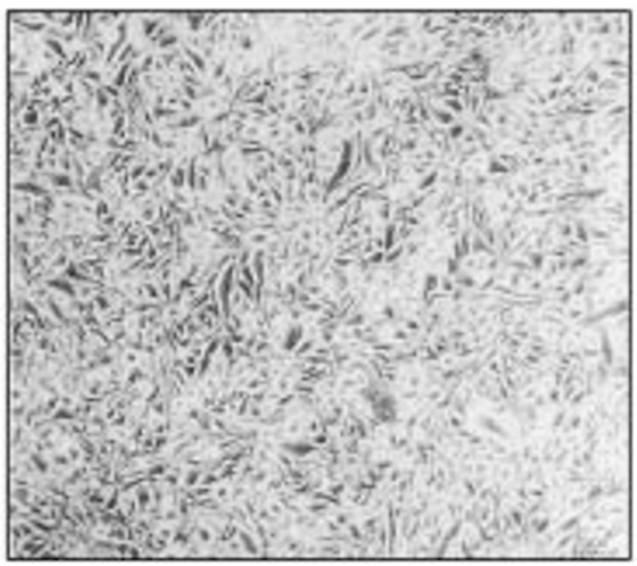

B.

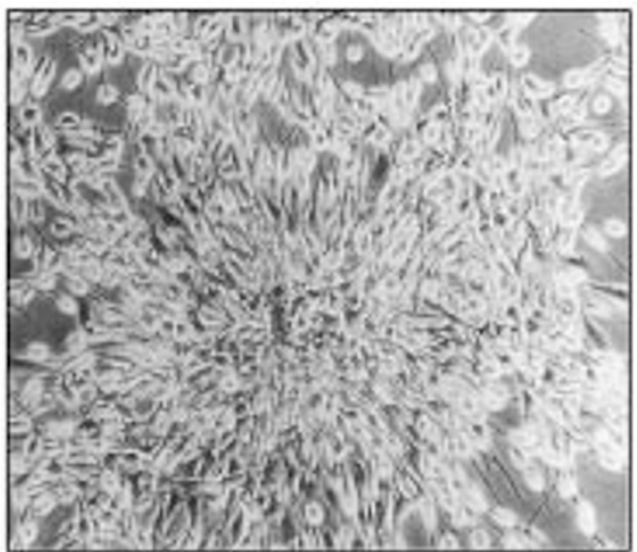

Figure 1. ras dependent transformation of $\mathrm{NIH} 3 \mathrm{~T} 3$ cells. (A) Non-transformed cells, (B) ras-transformed cells. NIH $3 \mathrm{~T} 3$ or ras transformed NIH3T3 cells were maintained in DMEM containing 10\% FCS and G418 as described in "Materials and Methods", and viewed by phase-contrast microscopy and photographed. Neo stands for cells harboring control neomycin gene and Ras represents ras-transformed cells. Magnification, $\times 400$.

whether the phenotypic changes were caused by ras oncogene, PCR was performed and found that the ras gene was uniquely detected in ras-transformed cells. This typical transformation model was used for assessing activation of MAPK module kinases. The ras-transformed cells showed an ability to form colonies in soft agar whereas no growth was observed by non-transformed cells (Ahn et al., 1995).

\section{Status of MAPK module in ras-transformed cells}

To examine whether the MAPK modules were activated either by mitogenic stimuli or transformation signal generated by ras, we first analyzed levels of total and phosphorylated form of ERK1/2 MAP kinases. The NIH3T3 cells transformed with neomycin resistant gene followed by neomycin selection was used as a negative control. The levels of ERK $1 / 2$ as revealed by Western blot analysis were not different between $\mathrm{Neo}$ and Ras-transformed cells (Figure 2A). However, phosporylation of

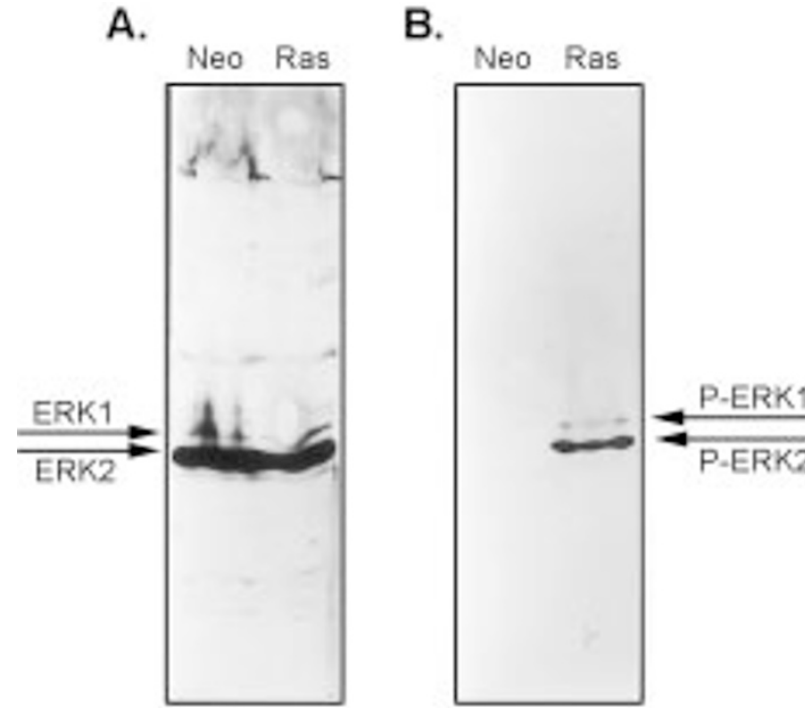

Figure 2. Expression and activation of MAPK in NIH3T3 cells transformed with ras proto-oncogene. NIH3T3 cells were cultured in DMEM containing $10 \%$ FCS and G418. Cell extracts were prepared as described in "Materials and Methods". ERKs (A) and phospho-ERK (B) proteins were detected by Western blot analysis using anti-ERK and anti-phospho-ERK antibodies respectively. Each $\mathrm{Neo}$ and Ras stands for cells harboring control neo gene and ras gene.

ERK1/2 MAPKs were observed in the ras-transformed $\mathrm{NIH} 3 \mathrm{~T} 3$ cells (Figure 2B).

To know the status of upstream MAPK module kinases, we checked expression levels of MEK and Raf1 kinases. Here, the Raf-1 was heavily expressed in both the neomycin resistant gene-transformed control and the ras-transformed NIH3T3 cells and did not show any significant differences in the levels of expression (Figure 3A). Interestingly, the level of MEK1 was distinctly observed only in the ras-transformed cell line (Figure 3B).

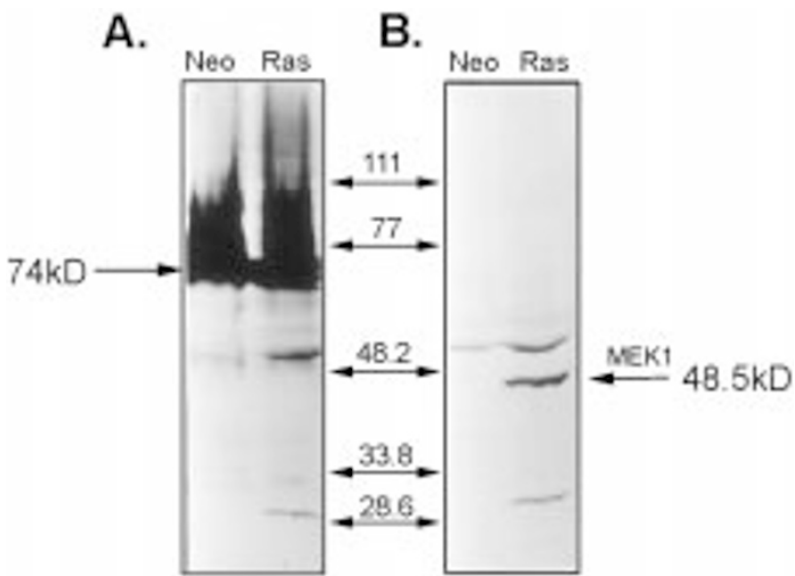

Figure 3. Expression of MAPK module kinases in ras transformed NIH3T3 cells. The Raf-1 (A) and MEK (B) proteins were detected by Western blot analysis by using anti-Raf-1 or anti-MEK antibodies, respectively. Cell growth conditions are same as described in Figure 2. 


\section{Effect of transformation on the molecular assembly of MAPK modules}

To better understand how Ras affects MAPK module components (MEK, Raf-1, and ERKs) for transformation of the cells, a possible selective high affinity association of these proteins was carried out by the glycerol gradient ultacentrifugation. This centrifugation method allows the separation and estimation of relative molecular sizes of protein entities present in the mixture of protein solution of the cell lysates but it is not an equilibrium sedimentation method and it only measures molecular entity in a very high affinity association such as in the intermolecular association of homodimer, homo-tetramers whose association constant exceeds 10-9. In this approach, we could estimate the molecular weight of the native proteins and possibly other protein complexes. As shown in Figure 4A, the ERK1/2 MAPKs is mostly appeared at the peak of molecular weight around $80 \mathrm{kD}$ and it suggests that the ERK $1 / 2$ ( 41 or $44 \mathrm{kD}$ proteins) may present as dimer or interact with other proteins with a high affinity in similar sized ERKs. However, the distribution of $80 \mathrm{kD}$ molecules in a few fractions that were not significantly changed when cells were treated by EGF. The dimeric complex may be stable and may not dissociated after EGF signal transduction. Intere-

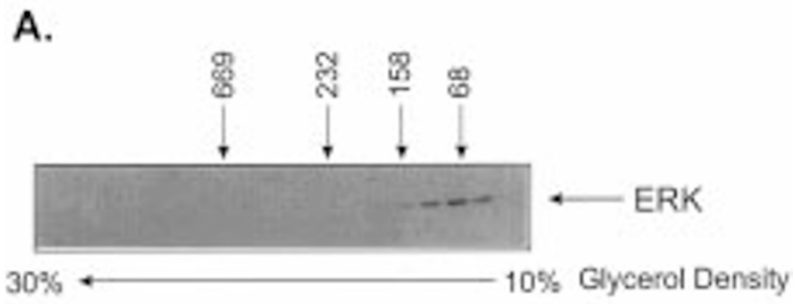

B.

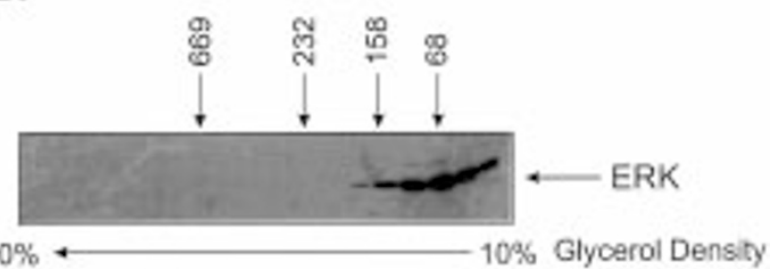

Figure 4. Effect of EGF in the glycerol gradient profile of ERK MAPK. One hundred and fifty microliter of cell extracts $(10 \mathrm{mg} / \mathrm{ml})$ were subjected to 10 $30 \%$ glycerol gradient $(\mathrm{w} / \mathrm{v})$ in $\mathrm{H}$ buffer containing $150 \mathrm{mM} \mathrm{NaCl}$ and protease inhibitors (see Materials and Methods). Molecular weight standards were loaded onto an indentical 10-30\% glycerol gradient and used as native molecular weight size markers. Samples were separated by ultracentrifugation and fractionated as described in "Materials and Methods". Each aliquots of the fractions $(150 \mu \mathrm{l})$ was used for immunoblot analysis. The ERK proteins were detected by anti-ERK polyclonal antibody. NIH3T3 Cells were grown in DMEM containing $10 \%$ FCS without (A) and with (B) EGF. For mitogen stimulation, $100 \mathrm{ng} / \mathrm{ml}$ of EGF were treated before harvesting the cells. Numbers on the top of panel represent the peaks of molecular weight standards in a glycerol gradient. $669 \mathrm{kD}$, Thyroglobulin; $232 \mathrm{kD}$, catalase; $158 \mathrm{kD}$, aldolase; $68 \mathrm{kD}$, albumin.
A.

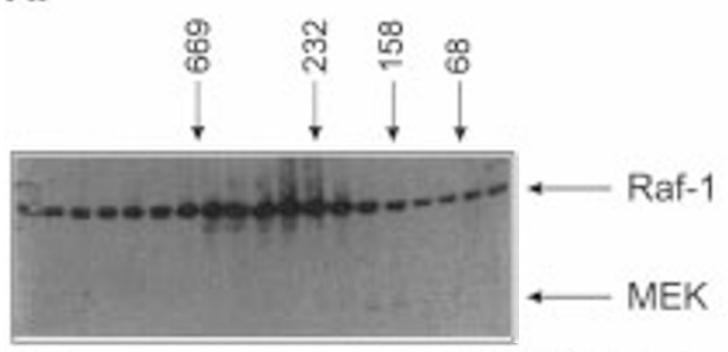

$30 \% \longleftarrow 10 \%$ Glycerol Density

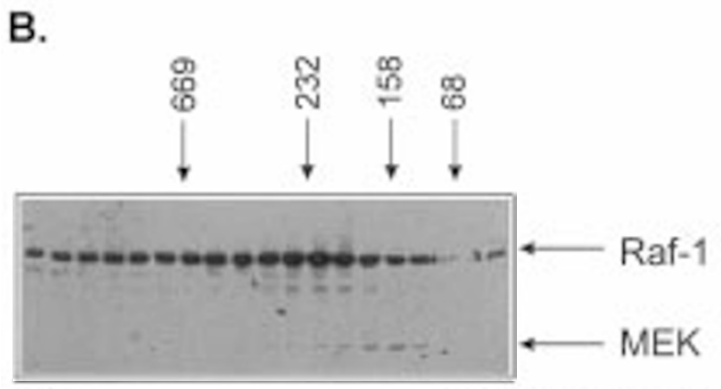

$30 \% \longleftarrow 10 \%$ Glycerol Density

Figure 5. The effect of EGF in the glycerol gradient profile of Raf-1 and MEK1 kinases. Experimental protocols were performed same as described in Figure 4. Each panel $\mathbf{A}$ and $\mathbf{B}$ represent non-induced or induced sample by EGF, respectively. The Raf- 1 and MEK proteins were detected by Western blot analysis using the mixture of anti-Raf-1 and anti-MEK antibodies. Numbers on the top of panel represent the peaks of molecular weight standards in a glycerol gradient as described in Figure 4.

stingly, the Raf-1 proteins were distributed broadly by the glycerol gradients (Figure 5A). However, the MEK protein appeared at the narrow ranges of the glycerol gradient, and peaked at the molecular weight size of $150 \mathrm{kD}$. The pattern of distribution profiles of both Raf1 and MEK were not significantly changed in the EGF induced cells (compare Figure 5A and 5B).

\section{Discussion}

Mitogen-activated protein kinases (MAPKs), also described as extra-cellular signal regulated kinases (ERKs) belong to a group of proteins known as serine/threonine kinases and its activational status is a determining factor for signal transduction (Blenis, 1993; Burgering et al., 1993; Egan et al., 1993; Pages et al., 1993; Cobb et al., 1995). The MAPK pathway is activated by various external stimuli including growth factors and neurotransmitters (Burgering et al., 1993; Egan et al., 1993; Stevenson et al., 1994). Ras is also one of the central components of the ERK MAPK signaling pathway, and its constitutively active mutations were found in numerous human cancers (Bos, 1989). Activation of ras is characterized by activation of downstream MAPK mo- 
dule kinases through series of phosphorylation cascade, Raf-1 $\rightarrow$ MEK $\rightarrow$ ERK. Understanding of how ras interact with MAPK kinases will help to design and develop novel approaches for cancer treatment by blocking the excess growth stimulation that might be caused by Ras (Levitzki et al., 1995).

To understand the role of ras in the cellular transformation, we have established ras transformed NIH3T3 cells. The ras transformed cells grow fast and changed its morphology characterized by formation of numerous spikes at the edges of cells. Furthermore, the cells were polarized to aggregate. The phenotypic change of ras transformed cells was confirmed by amplifying the gene using PCR. To understand roles of Ras in the activation of MAPK cascade, we checked status of MAPK module kinases by Western blot analysis of ras transformed or control NIH3T3 cells. In this experiment, we have found a significant activation of ERK1/2 MAPKs in the ras transformed cells, which is evident by phosphorylation of the protein (Figure 2B). The phospho-ERK MAPKs were not significantly observed in normal NIH3T3 cells although similar levels of the ERK proteins were found in both ras transformed and non-transformed cells (Figure $2 \mathrm{~A}$ and $2 \mathrm{~B}$ ). Therefore, Ras dependent activation of MAPKs may be caused by phosphorylation of the proteins rather than the increase in the levels of ERK proteins. To investigate the status of other upstream MAPK module kinases in the ras transformed cells, we performed Western blot analysis of the Raf-1 and MEK proteins. Although the Raf-1 and ERK proteins did not change its protein levels significantly, MEK protein was highly induced in Ras transformed cells. The increased level of MEK in Ras transformed NIH3T3 cells suggests that the MEK protein may be overexpressed or stabilized in Ras transformed cell. There is no report suggesting the overexpression of MEK is directly related to tumorigenesis. However, several reports show that the overexpression of wild-type MEK1 markedly enhanced the transforming efficiency of Mos (Okazaki et al., 1995), and MEK 1 could confer both tumorigenic and metastatic potential upon NIH3T3 cells Ras-independently (Welch et al., 2000). The maintenance of the high level of MEK depends on Ras transformation. Therefore, the high level of MEK dependent Ras could be important for the activation of the MAP kinase signaling cascade to involve transformation of the cells. But, further investigations are required to know whether the high level of MEK is acquired by gene expression or protein stability in Ras transformed cell.

Previous studies suggested possibilities of the presence of the complex between MAPK module kinases (Seger et al., 1992; Matsuda et al., 1993). Here, we investigated the presence of high affinity complexes among MAPK module kinases (Raf-1, MEK, and ERKs) in the NIH 3T3 cells. Furthermore, we also checked any changes in the status of the complex (es) by modulating the MAPK signal transduction. Here, we used EGF which is a well known initiator of MAPK signal transduction (Seger et al., 1992; Burgering et al., 1993). In 10-30\% glycerol gradient, the ERK $1 / 2$ MAPK kinases were mostly sedimented at the position of molecular weight about 80 $\mathrm{kD}$ (Figure $4 \mathrm{~A}$ ). This suggests that the ERK1/2 (41 or 44 $\mathrm{kD}$ proteins) may present as homo-dimer or interact with other proteins with high affinity in similar sized ERKs.

Our gradient centrifugation results of the Raf-1 protein distributed broadly on a glycerol gradient suggest that the Raf-1 may likely be involved in the formation of the high molecular weight complex(es) or the nonspecific association with many of the common cellular proteins. The Raf-1 protein are known to translocate to the membrane where numerous proteins, for example, cytoskeletal proteins are present for maintenance of cellular structure (Daum et al., 1994) and is known to interact with other Ras independent signaling molecules for activation of MAPKs (Burgering et al., 1993; Marquardt et al., 1994; Dent et al., 1995; Yao et al., 1995). The MEK protein located at the peak of $150 \mathrm{kD}$ suggest that the protein $(48 \mathrm{kD})$ may exist as multimeric forms or may present as a complex with other proteins, ERK or others. Here, distribution profiles of Raf- 1 and MEK proteins were not significantly changed under a condition induced by EGF (compare Figures $5 \mathrm{~A}$ and $5 \mathrm{~B}$ ). Several possibilities are suggested for reasons of not being able to detect the changes. First, the signal mediated molecular assembly of the proteins may be a transient event (Marshall, 1995), therefore, the change was not sensitively detected in our assay system. Secondly, it is also possible that quantity of proteins used for switching protein-protein interaction may be relatively small compared to the total levels of the proteins.

It was reported that the MAPK module kinase proteins were used for other cellular functions except Ras-dependent MAPK signaling for cell growth control (Burgering et al., 1993; Dent et al., 1995; Yao et al., 1995).

\section{Acknowledgement}

This study was supported in part by Korea Research Foundation grant (KRF-1995-021-F-0123).

\section{References}

Ahn, Y. H., Choi, J. W., Yoon, D. J., Lee, H. W., Han, D. P. and Kim, Y. S. (1995) Antisense GLUT1 RNA suppresses the transforming phenotype of NIH 3T3 cells transformed by $\mathrm{N}$-ras. Yonsei Med. J. 36: 480-486

Anderson, N. G., Maller, J. L., Tonks, N. K. and Sturgill, T. W. (1990) Requirement for integration of signals from two distinct phosphorylation pathways for activation of MAP kinase. Nature 343: 651-653 
Bargmann, C. L., Hung, M. C. and Weinberg, R. A. (1986) Multiple independent activation of the neu oncogene by point mutation altering the transmembrane domain of p185. Cell 45: 649-657

Blenis, J. (1993) Signal transduction via the MAP kinases: proceed at your own RSK. Proc. Natl. Acad. Sci. USA 90: 5889-5892

Bos, J. L. (1989) Ras oncogenes in human cancer: a review. Cancer Res. 49: 4682-4689

Burgering, B. M. T., de Vries-smith, A. M., Medema, R. H., van Weeren, P. C., Tertoolen, L. G. and Bos, J. L. (1993) Epidermal growth factor induced phosphorylation of extracellular signal-regulated kinase 2 via multiple pathways. Mol. Cell. Biol. 13: 7248-7256

Chang, E. H., Furth, M. E., Scolnick, E. M. and Lowy, D. R. (1982) Tumorigenic transformation of mammalian cells induced by a normal human gene homologous to the oncogene of Harvey murine sarcoma virus. Nature 297: 479-483

Cobb, M. H. and Goldsmith, E. J. (1995) How MAP kinases are regulated. J. Biol. Chem. 270: 14843-14846

Daum, G., Eisenmann-Tappe, I., Fries, H-W., Troppmair, J. and Rapp, U. R. (1994) The ins and outs of Raf kinases. Trends Biochem. Sci. 19: 474-479

Davis, R. J. (1993) The mitogen-activated protein kinase signal transduction pathway. J. Biol. Chem. 268: 14553-14556

Dent, P., Jelinek, T., Morrison, D. K., Weber, M. J. and Sturgill, T. W. (1995) Reversal of Raf-1 activation by purified and membrane-associated protein phosphatase. Science 268: 1902-1905

Egan, G. E. and Weinberg, R. A. (1993) The pathway to signal achievement. Nature 365: 781-783

Elion, E. A., Sattererg, B. and Kranz, J. E. (1993) FUS3 phosphorylates multiple components of the mating signal transduction cascade: evidence for STE12 and FAR1. Mol. Biol. Cell. 4: 495-510

Gallego, C., Gupta S. K., Heasley L. E., Qian N. and Johncon G. L. (1992) Mitogen activated protein kinase activation resulting from selective oncogene expression in NIH 3T3 and Rat 1a cells. Proc. Natl. Acad. Sci. USA 89: 7355-7359

Hall, A. (1993) Ras-related proteins. Curr. Biol. 5: 265-268

Janes, P. W., Daly, R. J., deFazio, A. and Sutherland, R. L. (1994) Activation of the Ras signalling pathway in human breast cancer cells overexpressing erbB-2. Oncogene 9: 3601 $-3608$

Land, H., Parada, H. F. and Weinberg, R. A. (1983) Tumorigenic conversion of primary embryo fibroblasts requires at least two operating oncogenes. Nature 304: 596-602

Levitzki, A. and Gazit, A. (1995) Tyrosine kinase inhibition: an approach to drug development. Science 267: 1782-1788

Linzer, D. I. H. and Levine, A. Z. (1979) Characterization of a $54 \mathrm{k}$ dalton cellular SV40 tumor antigen present in SV40 transforned cells and uninfected embryonal carcinoma cells. Cell 17: 43-52
Marquardt, B., Fritch, D. and Stabe, I. S. (1994) Signalling from TPA to MAP kinase requires protein kinase $\mathrm{C}$, raf and MEK: Reconstitution of the signalling pathway in vitro. Oncogene 9: 3213-3218

Marshall, C. J. (1995) Specificity of receptor tyrosine kinase signaling: transient versus sustained extracellular signal-regulated kinase activation. Cell 80: 179-185

Matsuda, S., Gotoh, Y. and Nishida, E. (1993) Phosphorylation of Xenopus mitogen-activated protein (MAP) kinase kinase by MAP kinase kinase kinase and MAP kinase. J. Biol. Chem. 268: 3277-3281

Moon, Y. A., Kim, K. S., Cho, U. H., Yoon, D. J. and Park, S. W. (1999) Characterization of regulatory elements on the promoter region of human ATP-citrate lyase. Exp. Mol. Med. 31: 108-114.

Murray, M. J., Cunningham, J. M., Parada, L. F., Dautry, F., Lebowiz, P. and Weinberg, R. A. (1983) The HL-60 transforming sequence; a ras oncogene coexisting with altered myc gene in hematopoietic tumors. Cell 33: 749-757

Okazaki, K. and Sagata, N. (1995) MAP kinase activation is essential for oncogenic transformation of NIH3T3 cells by Mos. Oncogene 16: 1149-1157

Pages, G., Lenormand, P., L'Allemain, G., Ghambard, J-G. and Meloche, S. (1993) Mitogen-activated protein kinases $\mathrm{p} 42^{\mathrm{mapk}}$ and $\mathrm{p} 44^{\mathrm{mapk}}$ are required for fibroblast proliferation. Proc. Natl. Acad. Sci. USA 90: 8319-8323

Payne, D. M., Rossomando, A. J., Martino, P., Erickson, A. K., Her, J-H., Shabanowitz, J., Hunt, D. F., Weber, M. J. and Sturgill, T. W. (1991) Identification of the regulatory phosphorylation sites in pp42/mitogen-activated protein kinase (MAP kinase). EMBO J. 10: 885-892

Pelech, S. L. and Sanghera, J. S. (1992) Mitogen-activated protein kinases: versatile transducers for cell signaling. Trends Biochem. Sci. 17: 233-238

Ricketts, M. H. and Levinson, A. D. (1988) High level exposure of $\mathrm{C}-\mathrm{H}-\mathrm{ras}$ fails to fully transform Rat-1 cells. Mol. Cell. Biol. 8: $1460-1480$

Ruley, H. E. (1983) Adenovirus early region 1A enables viral and cellular transforming genes to transform primary cells in culture. Nature 304: 602-606

Seger, R., Ahn, N. G., Posada, J., Munar, E. S., Jensen, A. M., Cooper, J. A., Cobb, M. H. and Krebs, E. G. (1992) Purification and characterization of mitogen-activated protein kinase activator(s) from epidermal growth factor-stimulated A431 cells. J. Biol. Chem. 267: 14373-14381

Slamon, D. J., Godolphin, W., Jones, L. A., Wong, S. G., Keith, D. E., Levin, W. J., Stuart, S. G., Udove, J., Ullrich, A. and Press, M. F. (1989) Studies of the HER-2 neu protooncogene in human breast and ovarian cancer. Science 244 : 707-712

Stevenson, M. A., Pollock, S. S., coleman, C. N. and Calderwood, S. K. (1994) X-irradiation, phorbolester, and $\mathrm{H}_{2} \mathrm{O}_{2}$ stimulate mitogen-activated protein kinase activity in $\mathrm{HIH}-3 \mathrm{~T} 3$ cells through the formation of reactive oxygen inter- 
mediates. Cancer Res. 54: 12-15

Tsutsumi, Y., Naber, S. P., DeLellis, R. A., Wolfe, H. J., Marks, P. J., McKenzie, S. J. and Yin, S. (1990) Neu oncogene protein and epidermal growth factor receptor are independently expressed in benign and malignant breast tissue. Hum. Pathol. 21: 750-758

Welch, D. R, Sakamaki, T., Pioquinto, R., Leonard, T. O., Goldberg, S. F., Hon, Q., Erikson, R. L., Rieber, M., Rieber, M.
S., Hicks, D. J., Bonventre, J. V. and Alessandrini, A. (2000) Transfection of constitutively active mitogen-activated protein/ extracellular signal-regulated kinase kinase confers tumorigenic and metastatic potentials to NIH3T3 cells. Cancer Res. 15: $1552-1556$

Yao, B., Zhang, Y., Dellkat, S., Mathias, S., Basu, S. and Kolesnick, R. (1995) Phosphorylation of Raf by ceramideactivated protein kinase. Nature 378: $307-310$ 